\title{
KARAKTERISTIK MAHASISWA \\ PENDIDIKAN MATEMATIKA IAIN ANTASARI BANJARMASIN DENGAN MENGGUNAKAN METODE TWO STEP CLUSTER (Studi Kasus Angkatan 2012/2013)
}

\author{
Sessi Rewetty Rivilla (Ketua), Rahmawati, Lathifaturrahmah
}

\begin{abstract}
Abstrak
Kehomogenan karakteristik dalam suatu kelas sangat diperlukan agar hasil belajar dapat lebih ditingkatkan. Untuk itu, diperlukan suatu pengelompokkan mahasiswa yang menghasilkan kelompok-kelompok yang lebih homogen berdasarkan karakteristik yang dimilikinya, hal ini dapat dilakukan dengan metode pengelompokan, salah satunya dengan metode two step cluster. Tujuan dari penelitian ini adalah untuk mengetahui karakteristik mahasiswa Pendidikan Matematika Angkatan 2012/2013 Fakultas Tarbiyah dan Keguruan IAIN Antasari Banjarmasin dengan menggunakan metode Two Step Cluster.

Berdasarkan hasil penelitian diperoleh karakteristik Cluster 1 berisi 100\% mahasiswa yang berasal dari jalur masuk PSB, jurusan IPA, berstatus negeri, dan biaya kuliah berasal dari orang tua. Berasal dari sekolah yang terletak di luar Kabupaten Banjar sebesar 92\%, memiliki rata-rata nilai matematika di rapor yaitu 8,54, dan nilai UN matematika 8,39 , dan paling banyak berjenis kelamin perempuan yaitu $68 \%$. Sedangkan untuk profil Cluster 2 berisi 100\% dari sekolah berstatus negeri dan biaya kuliah dari orang tua, mahasiswa yang berasal dari jalur masuk SPMB-PTAIN sebesar $80 \%$, rata-rata nilai rapor 7,99 , berasal dari jurusan IPA sebesar 74,3\%, 80\% berasal dari Luar Kabupaten Banjar, berjenis kelamin perempuan sebesar $68,6 \%$ dan memiliki nilai UN Matematika yaitu 7,95. Karakteristik Cluster 3 berisi mahasiswa yang berasal dari sekolah swasta sebesar $56,8 \%$, dari jurusan IPA sebesar 47,7\%, berasal dari sekolah Luar Kabupaten Banjar sebesar 38,6\%. Biaya kuliah berasal dari orang tua sebesar $72,7 \%$, berasal dari jalur masuk SPMB PTAIN sebesar $70,5 \%$, dan mempunyai nilai UN Matematika 7,79 dan rata-rata nilai rapor 8,37 dan berjenis kelamin perempuan sebanyak $72,7 \%$.
\end{abstract}

Kata Kunci: Karakteristik Mahasiswa, dan Metode Two Step Cluster 


\section{Pendahuluan}

Jurusan Pendidikan Matematika merupakan salah satu jurusan yang berada di Fakutas Tarbiyah dan Keguruan IAIN Antasari Banjarmasin. Jurusan ini berdiri pada tahun 1999. Semenjak berdiri hingga sekarang jumlah mahasiswa jurusan Pendidikan Matematika terus bertambah, ini dibuktikan dengan meningkatnya peminat calon mahasiswa baru jurusan Pendidikan Matematika. Seiring dengan meningkatnya kuantitas mahasiswa, diperlukan juga peningkatan kualitas hasil belajar mahasiswa. Agar kualitas mahasiswa dapat ditingkatkan, maka banyak aspek yang harus diperhatikan, baik itu dari segi pengajar, mahasiswa, sarana dan prasarana.

Sebelum melakukan proses pengajaran tenaga pengajar kiranya perlu mengetahui karakteristik-karakteristik dari mahasiswa-mahasiswanya, hal ini dilakukan agar tenaga pendidik dapat menentukan strategi dan metode dalam melaksanakan proses pembelajaran. Kehomogenan karakteristik dalam suatu kelas sangat diperlukan agar hasil belajar dapat lebih ditingkatkan, untuk itu diperlukan suatu pengelompokkan mahasiswa yang menghasilkan kelompok-kelompok yang lebih homogen berdasarkan karakteristik yang dimilikinya, hal ini dapat dilakukan dengan metode pengelompokan atau penggerombolan. Metode ini lebih dikenal dengan analisis cluster atau analisis gerombol.

Analisis cluster adalah analisis peubah ganda yang digunakan untuk mengelompokkan objek-objek menjadi beberapa gerombol berdasarkan pengukuran kemiripan peubah-peubah yang diamati, sehingga diperoleh kemiripan objek dalam gerombol yang sama dibandingkan antar objek dari gerombol yang berbeda. Salah satu jenis analisis cluster adalah metode two step cluster. Metode ini dikembangkan oleh Chiu et al yang memungkinkan untuk mengolah data dengan tipe peubah yang berbeda yaitu kontinu dan kategorik.

Berdasarkan uraian di atas, peneliti tertarik untuk melakukan penelitian di jurusan Pendidikan Matematika IAIN Antasari Banjarmasin dengan judul "Karakteristik Mahasiswa Pendidikan Matematika IAIN 
Karakteristik Mahasiswa Pendidikan Matematika IAIN Antasari Banjarmasin Dengan Menggunakan Metode Two Step Cluster

(Studi Kasus Angkatan 2012/2013)

Antasari Banjarmasin dengan Menggunakan Metode Two Step Cluster (studi kasus angkatan 2012/2013)”.

\section{Tujuan Penelitian}

Penelitian ini bertujuan untuk mengetahui karakteristik mahasiswa Pendidikan Matematika Angkatan 2012/2013 Fakultas Tarbiyah dan Keguruan IAIN Antasari Banjarmasin dengan menggunakan metode Two Step Cluster.

\section{Rumusan Masalah}

Bagaimana karakteristik mahasiswa Pendidikan Matematika Angkatan 2012/2013 Fakultas Tarbiyah dan Keguruan IAIN Antasari Banjarmasin dengan menggunakan metode Two Step Cluster?

\section{Manfaat Penelitian}

Penelitian ini bermanfaat bagi:

1. Pengembangan jurusan Pendidikan Matematika Fakultas Tarbiyah dan Keguruan IAIN Antasari Banjarmasin terutama dalam mengetahui informasi karakteristik mahasiswa jurusan Pendidikan Matematika.

2. Dengan mengetahui karakteristik mahasiswa Pendidikan Matematika dengan metode two step clustering, informasi tersebut dapat dijadikan bahan pertimbangan dalam penerimaan calon mahasiswa baru yang akan datang.

3. Pengelompokan kelas berdasarkan karakteristik mahasiswa yang lebih homogen dapat meningkatkan kualitas hasil belajar mahasiswa

4. Strategi promosi jurusan Pendidikan Matematika Fakultas Tarbiyah dan Keguruan IAIN Antasari Banjarmasin 
Sessi Rewetty Rivilla, Lathifaturrahmah, Rahmawati

\section{Laporan Hasil Penelitian}

\section{Hasil Cluster}

Pembentukan cluster sebanyak 3 cluster. Pembentukan ini didasarkan pada pertimbangan banyaknya kelas yang disediakan oleh pihak rektorat dan jumlah mahasiswa yang terdaftar. Hal ini dilakukan, agar dalam kegiatan pembelajaran di dalam kelas dapat dilaksanakan secara optimal. Setelah dilakukan proses clustering maka diperoleh hasil sebagai berikut:

Tabel 1. Cluster Distribution

\begin{tabular}{|c|c|c|c|}
\hline & $N$ & $\begin{array}{c}\text { \% of } \\
\text { Combined }\end{array}$ & $\begin{array}{l}\text { \% of } \\
\text { Total }\end{array}$ \\
\hline 1 & 25 & $24,0 \%$ & $23,8 \%$ \\
\hline 2 & 44 & $42,3 \%$ & $41,9 \%$ \\
\hline 3 & 35 & $33,7 \%$ & $33,3 \%$ \\
\hline Combined & 104 & $100,0 \%$ & $99,0 \%$ \\
\hline Excluded Cases & 1 & & $1,0 \%$ \\
\hline Total & 105 & & $100,0 \%$ \\
\hline
\end{tabular}

Dari tabel 1 di atas dapat dilihat bahwa mahasiswa terbanyak ada di cluster 2 yakni berjumlah 44 orang atau 42\%, sedangkan mahasiswa yang paling sedikit ada di cluster 1 yakni berjumlah 25 orang atau 24\%, sedangkan cluster 3 berjumlah 35 orang atau sebesar 33,7\% dari 105 orang, dan 1 data yang tidak dapat dipetakan ke dalam salah satu cluster karena data yang dimiliki tidak lengkap. Untuk lebih jelasnya dapat dilihat pada pie chart berikut ini: 
Karakteristik Mahasiswa Pendidikan Matematika IAIN Antasari Banjarmasin Dengan Menggunakan Metode Two Step Cluster

(Studi Kasus Angkatan 2012/2013)

\section{Cluster Sizes}

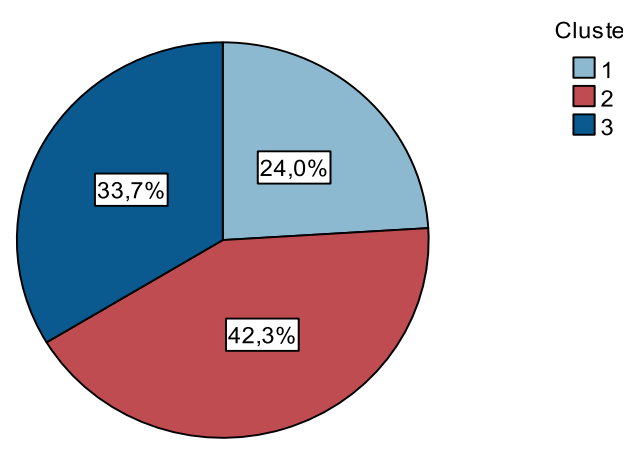

Gambar 1. Grafik Distribusi Ukuran Cluster

\section{Tafsiran setiap cluster.}

\begin{tabular}{|c|c|c|c|}
\hline & & \multicolumn{2}{|c|}{$\begin{array}{l}\text { Input (Predictor) Importance } \\
\square 1.0 \square 0.8 \square 0.6 \square 0.4 \square 0.2 \square 0.0\end{array}$} \\
\hline $\begin{array}{l}\text { Cluster } \\
\text { Labal }\end{array}$ & 2 & 3 & 1 \\
\hline Deseription & & & \\
\hline Sices & D $42,3 x$ & $733.7 \times$ & $24,0.25$ \\
\hline Inpule & spmialur Mestak & 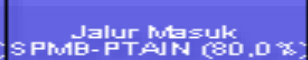 & 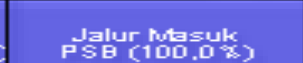 \\
\hline & $\begin{array}{l}\text { Status sekolah } \\
\text { Swasta (56.8\%k) }\end{array}$ & $\begin{array}{l}\text { Status sekolah } \\
\text { Negien (100.0x) }\end{array}$ & $\begin{array}{l}\text { Status sekolah } \\
\text { Negien (100.0 }\end{array}$ \\
\hline & IP'A(47.7 $x)$ & Ifarysan & IP Jurusan \\
\hline & $\begin{array}{l}\text { Asal Sekolah } \\
\text { Lur Kat Eanjar } \\
\text { (38.6 }\end{array}$ & $\begin{array}{l}\text { Asal Sekolah } \\
\text { Lar Kab Qanjar } \\
\text { (Bo.0 }\end{array}$ & $\begin{array}{l}\text { Asal Sekolah } \\
\text { Lua Kab Banjar } \\
\text { (92.0 By }\end{array}$ \\
\hline & Rata nilai matk rapot & Rata nilai matk rapot & Rata nilai matk rapot \\
\hline & $\begin{array}{l}\text { Biaya Kuliah Berasal } \\
\text { Orang Tuari }(72.7 x)\end{array}$ & $\begin{array}{l}\text { Biaya Kuliah Berasal } \\
\text { Orang Tuari (100.0x) }\end{array}$ & $\begin{array}{l}\text { Biaya Kuliah Berasal } \\
\text { Orang Tuari }(100.0 x)\end{array}$ \\
\hline & Nilai UN & Nilai $\frac{1}{7.95}$ metk & Nilai UN matk \\
\hline & $\begin{array}{l}\text { Jenis kelamin } \\
\text { Perempuan }(72,7 x)\end{array}$ & $\begin{array}{l}\text { Jenis kelamin } \\
\text { Perempuan (68.6) }\end{array}$ & 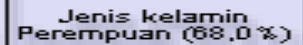 \\
\hline
\end{tabular}




\section{a. Cluster 1:}

Cluster 1 berisi mahasiswa yang berasal dari jalur masuk PSB sebesar $100 \%$, berasal dari jurusan IPA sebesar 100\%, berasal dari sekolah berstatus negeri $100 \%$, berasal dari sekolah yang terletak di luar Kabupaten Banjar sebesar 92\%, memiliki rata-rata nilai matematika di rapor yaitu 8,54 dan nilai UN matematika 8,39 . Biaya kuliah $100 \%$ berasal dari orang tua, serta $68 \%$ berjenis kelamin perempuan.

Berdasarkan rata-rata nilai matematika di rapor pada cluster 1 ini, dapat dilihat tergolong lebih besar jika dibandingkan dengan rata-rata nilai matematika di rapor pada cluster 2 dan cluster 3. Berdasarkan ciri-ciri di atas, mahasiswa-mahasiswa yang berada pada cluster 1 diduga memiliki hasil belajar yang lebih tinggi dibandingkan dengan mahasiswa pada cluster yang lain.

b. Cluster 2:

Cluster 2 berisi mahasiswa yang berasal dari jalur masuk SPMBPTAIN sebesar $80 \%$, berasal dari sekolah berstatus negeri $100 \%$, rata-rata nilai rapor 7,99, berasal dari jurusan IPA sebesar 74,3\%, sebesar $80 \%$ berasal dari luar Kabupaten Banjar. Biaya kuliah 100\% berasal dari orang tua, berjenis kelamin perempuan sebesar $68,6 \%$ dan memiliki nilai UN Matematika yaitu 7,95 .

Berdasarkan rata-rata nilai matematikanya di rapor pada cluster 2 ini, dapat dilihat tergolong tidak lebih besar dengan nilai matematika di rapor pada cluster 3. Demikian halnya dengan jenis kelamin. Berdasarkan ciri-ciri di atas, mahasiswa-mahasiswa yang berada pada cluster 2 diduga memiliki hasil belajar yang lebih rendah dibandingkan dengan mahasiswa pada cluster 1.

\section{c. Cluster 3:}

Cluster 3 berisi mahasiswa yang berasal dari sekolah swasta sebesar $56,8 \%$, dari jurusan IPA sebesar 47,7\%, berasal dari sekolah luar Kabupaten Banjar sebesar 38,6\%. Biaya kuliah berasal dari orang tua sebesar 72,7\%, berasal dari jalur masuk SPMB PTAIN sebesar 70,5\%, dan 
Karakteristik Mahasiswa Pendidikan Matematika IAIN Antasari Banjarmasin Dengan Menggunakan Metode Two Step Cluster (Studi Kasus Angkatan 2012/2013)

mempunyai nilai UN Matematika 7,79 dan rata-rata nilai rapor 8,37, serta berjenis kelamin perempuan sebanyak $72,7 \%$.

Berdasarkan rata-rata nilai matematikanya di rapor pada cluster 3 ini, dapat dilihat tergolong lebih besar jika dibandingkan dengan rata-rata nilai matematika di rapor pada cluster 2 , tetapi tidak lebih besar dibanding rata nilai rapor matematika pada cluster 1. Berdasarkan ciri-ciri di atas, mahasiswa-mahasiswa yang berada pada cluster 3 diduga memiliki hasil belajar yang lebih rendah dibandingkan dengan mahasiswa pada cluster 1.

1. Variabel yang mendorong pembentukan cluster

\section{Predictor Importance}

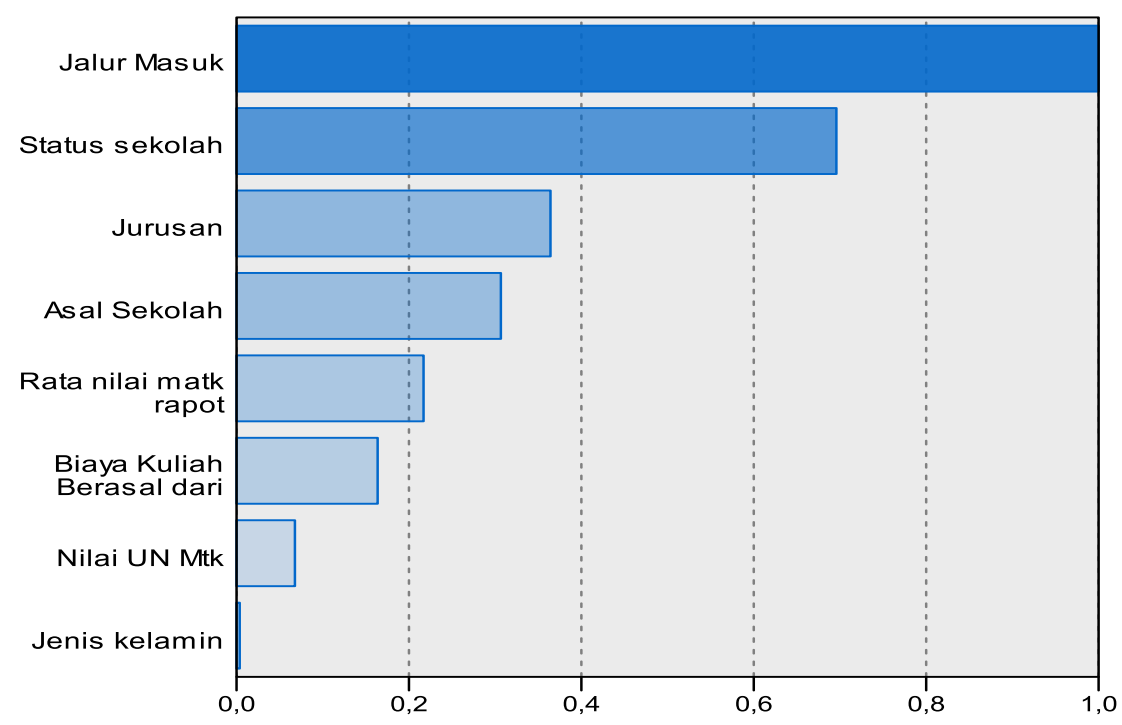

Least Important Most Important

Gambar 2. Grafik Variabel yang Mendorong Pembentukan Cluster

Berdasarkan grafik di atas variabel yang paling penting dalam pembentukan cluster ini adalah berasal dari jalur masuk, kemudian status sekolah, jurusan, asal sekolah, rata-rata nilai matematika di rapor, lalu biaya kuliah, nilai UN Matematika, dan terakhir jenis kelamin. 
Sessi Rewetty Rivilla, Lathifaturrahmah, Rahmawati

\section{Kesimpulan}

1. Kesimpulan

Berdasarkan penelitian di atas dapat disimpulkan karakteristik masing-masing cluster yaitu sebagai berikut:

a. Karakteristik Cluster 1 berisi 100\% mahasiswa yang berasal dari jalur masuk PSB, jurusan IPA, dan berasal dari sekolah berstatus negeri. Asal sekolah yang terletak di luar Kabupaten Banjar sebesar 92\%, memiliki rata-rata nilai matematika di rapor yaitu 8,54 dan rata-rata nilai UN matematika 8,39, serta biaya kuliah $100 \%$ berasal dari orang tua, dan berjenis kelamin perempuan sebesar $68 \%$.

b. Karakteristik Cluster 2 berisi mahasiswa yang berasal dari jalur masuk SPMB-PTAIN sebesar $80 \%$, berstatus negeri 100\%, rata-rata nilai rapor 7,99, berasal dari jurusan IPA sebesar 74,3\%, 80\% berasal dari Luar Kabupaten Banjar. Biaya kuliah 100\% beasal dari orang tua, berjenis kelamin perempuan sebesar $68,6 \%$ dan memiliki nilai UN Matematika yaitu 7,95.

c. Karakteristik Cluster 3 berisi mahasiswa yang berasal dari sekolah swasta sebesar $56,8 \%$, dari jurusan IPA sebesar $47,7 \%$, berasal dari sekolah Luar Kabupaten Banjar sebesar 38,6\%. Biaya kuliah berasal dari orang tua sebesar $72,7 \%$, berasal dari jalur masuk SPMB PTAIN sebesar 70,5\%, dan mempunyai nilai UN Matematika 7,79 dan ratarata nilai rapor 8,37 , serta berjenis kelamin perempuan sebanyak $72,7 \%$.

2. Saran

Berdasarkan hasil penelitian di atas dapat dikemukan saran sebagai berikut:

a. Bagi jurusan agar dapat memperhatikan pengelompokan masingmasing kelas untuk mahasiswa baru untuk tahun yang akan datang, berdasarkan tingkat kehomogenan mahasiswa, dan variabel yang mempengaruhi terbentuknya kelompok atau cluster tersebut. 
Karakteristik Mahasiswa Pendidikan Matematika IAIN Antasari Banjarmasin Dengan Menggunakan Metode Two Step Cluster (Studi Kasus Angkatan 2012/2013)

b. Bagi peneliti yang ingin mengadakan penelitian sejenis dapat menggunakan variabel yang lebih banyak lagi, tergantung tujuan penelitian yang ingin dilakukan.

c. Bagi dosen pengajar, hendaknya memilih strategi pembelajaran yang tepat berdasarkan karakteristik mahasiswa di kelas, sehingga diperoleh hasil yang maksimal dalan proses pembelajaran.

\section{Daftar Pustaka}

Anonimous. (2001). The SPSS TwoStep Cluster Component. A Scalable Component to Segment Your Costumers More Effectifely. White paper-technical report, SPSS Inc Chicago.

Bacher J, Wenzig K, Vogler M. (2004). SPSS TwoStep Cluster : A First Evaluation. Friedrich-Alexander-Universitat Erlangen-Nunberg.

Dillon WR, Goldstein M. (1984). Multivariate Analysis Method and Applications. John Wiley \& Sons. Canada.

Hong SL. (2006). Experiment With K-Means, Fuzzy C-Means and Approaches to Choose $K$ and $C$. University of Central Florida. Orlando.

James, W. B., \& Blank, W. E. (1993). Review and critique of available learningstyle instruments for adults. In D. Flannery (Ed.), Applying cognitive learning styles. San Francisco: Jossey-Bass.

Kusdiati. (2006). Pengkajian keakuratan TwoStep Cluster dalam menentukan banyaknya gerombol populasi [tesis]. Bogor: Program Pascasarjana, Institut Pertanian Bogor.

Kusumadewi S, Hartati S, Harjoko A. Wardoyo R. (2006). Fuzzy MultiAttribute Decision Making (FUZZY MADM). Yogyakarta. Graha Ilmu.

McLoughlin, C. (1999). The implications of research literature on learning styles for the design of instructional material. Australian Journal of Educational Technology, 15(3). 
Sessi Rewetty Rivilla, Lathifaturrahmah, Rahmawati

Sessi Rewetty Rivilla

IAIN Antasari, Banjarmasin

E-mail:-

\section{Rahmawati}

IAIN Antasari, Banjarmasin

E-mail: palimbangan_math@yahoo.com

\section{Lathifaturrahmah}

IAIN Antasari, Banjarmasin

E-mail: lathifah_02@yahoo.com 
Karakteristik Mahasiswa Pendidikan Matematika IAIN Antasari Banjarmasin Dengan Menggunakan Metode Two Step Cluster

(Studi Kasus Angkatan 2012/2013) 